\title{
Acoustic Surveys of Abundance and Distribution of the Japanese Sardine Sardinops melanostictus in the Spawning Grounds off Southern Kyushu, Japan
}

\author{
Ichiro Aoki*1 and Tadashi Inagaki*1 \\ (Received June 3, 1993)
}

\begin{abstract}
Distribution patterns of the spawning population of the Japanese sardine Sardinops melanostictus off southern Kyushu were investigated by the acoustic method in relation to water temperature and the Kuroshio current in three successive winters from 1990 to 1992. Acoustic data were obtained by single-beam $50 \mathrm{kHz}$ echo sounders interfaced to digital integrators. Sardine distribution varied during January-March as time advanced. It was closely associated with both water temperature and spawning activity. Maturing sardine stayed on the inshore side of the Kuroshio front while spawning sardine occurred in the higher temperature offshore waters further than the Kuroshio front that appear to have acted as a barrier to distribution previously. The fish abundance in the area of sardine concentration decreased markedly over the 3 years.
\end{abstract}

The Japanese sardine Sardinops melanostictus is one of the most important fish species in Japanese fisheries. Annual sardine catches in Japan reached their highest level of 4,490 thousand tons in 1988 . However, the catches began to decrease in 1989 , being 3,680 thousand tons in $1990,3,010$ thousand tons in 1991 and 2,300 thousand tons in 1992.

It has been known that during periods of high abundance, the spawning grounds of the Japanese sardine mainly occur in the area around southern Kyushu, southwestern Japan.1,2) In 1980 the main spawning grounds were formed off southern Kyushu as in the 1930s when population levels were high. Then the distributions of sardine eggs and larvae began to extend offshore in the main stream area of the Kuroshio current in 1983, this tendency showing a yearly increase in the 1980s. ${ }^{3)}$ Japanese sardine inhabit the inshore side of the Kuroshio current. ${ }^{4}$ They usually occur in a water temperature range of 10 to $17^{\circ} \mathrm{C}^{5}$ or 10 to $20^{\circ} \mathrm{C}$. ${ }^{\theta}$ The extension of the distribution into the Kuroshio area where temperature $>20^{\circ} \mathrm{C}$ appears to be a significant feature found only in the spawning season.

There has been limited information on the distribution of adult Japanese sardine in the spawning season. Kurodat? has reported on the occurrence of adult sardine collected by fishing in the Kuroshio area. However, detailed information on the abundance and distribution of pelagic fish in time and space would be difficult to obtain by fishing alone. Acoustic techniques provide rapid and continuous measurements throughout the water column and more complete information on the distribution and behavior of pelagic schooling fishes. This study investigated horizontal distribution patterns of spawning sardine in relation to water temperature and the Kuroshio current off southern Kyushu in three successive winters from 1990 to 1992 using the acoustic method.

\section{Materials and Methods}

Acoustic data on the spawning population of sardine were obtained during four cruises conducted in the area off southern Kyushu (Table 1). Single-beam $50 \mathrm{kHz}$ echo sounders were used: a Furuno FQ-50 mounted on the RV 'Tansei Maru' (470 t) and a Furuno FQ-71 on the RV 'Hakuho Maru' $(3,987 \mathrm{t})$. Each echo sounder was interfaced to a digital integrator, logging system, and personal computer. Transducers were hull-mounted. The acoustic systems processed echoes and output the mean volume backscattering strength $(S V$ in $\mathrm{dB})$ in real time for nine $10 \mathrm{~m}$ depth strata from 10 to $100 \mathrm{~m}$ at horizontal integration intervals of 0.2 or 0.4 nautical miles (nm). Acoustic surveys consisted of grid surveys with wide areal coverage and repeated surveys along a transect. The surveys were conducted in the

*1 Ocean Research Institute, University of Tokyo, Nakano, Tokyo 164, Japan (青梞一郎, 榣垣 正: 查京大学海洋研究所). 
Table 1. Dates of acoustic surveys, and settings and calibration parameters of acoustic equipment

\begin{tabular}{lrrrr}
\hline \multicolumn{1}{c}{ Cruise } & KT-90-3 & KT-91-1 & KH-91-2 & KT-92-3 \\
\hline Date & MAR 3-9, & JAN 20-23, & Leg 1 FEB 14-22, 1991 & FEB 25-MAR 3, \\
& 1990 & 1991 & & 1992 \\
& & & Leg 2 FEB 26-MAR 1, \\
& & & 1991 & Leg 3 MAR 9-14, 1991 \\
Echo sounder & & & FQ 71 & FQ 50 \\
Source level (dB) & FQ 50 & FQ 50 & 219.3 & 225.2 \\
Pulse duration (ms) & 223.0 & 223.3 & 1.2 & 1.2 \\
Equivalent ideal beam factor (dB) & 1.2 & 1.2 & -14.5 & -19.6 \\
Absorption coefficient (dB) & -19.6 & -19.6 & 14.3 & 12.0 \\
Receiving sensitivity (dB) & -18.0 & 12.0 & -184.2 & -182.8 \\
Amplifier gain (dB) & 49.2 & -182.4 & 46.8 & 49.2 \\
\hline
\end{tabular}

KT and KH denote RV 'Tansei-Maru', respectively.

daytime and night-time at a ship speed of about 10 knots.

The acoustic calibration of the systems was performed in port at Tokyo before each cruise for KT-91-1 and KH-91-2 or after each cruise for KT-90-3 and KT-92-3. Source level and receiving sensitivity were measured by means of a hydrophone, and the gain of amplifiers of the systems was also measured. Parameter settings of the acoustic systems are shown in Table 1.

The absorption coefficient requires attention because it depends on oceanographic conditions such as water temperature and salinity. The acoustic surveys were made with the absorption coefficient set by anticipation on the values in Table 1. The actual absorption coefficients based on oceanographic conditions were calculated using CTD data in the crusie KH-91-2 and Francois and Garrison's equation $^{8)}$ for two representative sites of the inshore and the Kuroshio regions: $13.75 \mathrm{~dB} /$ $\mathrm{km}$ for the inshore region and $12.75 \mathrm{~dB} / \mathrm{km}$ for the Kuroshio region in the range of 0 to $100 \mathrm{~m}$ depth. The setting values of the absorption coefficient in this study differed by $1.74 \mathrm{~dB} / \mathrm{km}$ at most from the calculated values. This difference corresponds to a bias of $0.174 \mathrm{~dB}(4 \%)$ at $50 \mathrm{~m}$ depth. There was a difference of $2.3 \mathrm{~dB} / \mathrm{km}$ in the absorption coefficient between the two acoustic systems, which corresponds to $0.23 \mathrm{~dB}(5 \%)$ at $50 \mathrm{~m}$ depth. Because this is likely to be a minor source of error in the 10 to $50 \mathrm{~m}$ depth range for which acoustic data were analyzed, no correction was made for the absorption coefficient.

Fish traces above $50 \mathrm{~m}$ depth on echograms were identified by a gill net, fishing lines, and underwater TV. Sardine predominated considerably in fish collections, while other fish species including mackerel, scads, and round herring occupied only a small portion of the collections. In addition, schooling sardine were observed consistently by the underwater TV. Therefore, fish traces above $50 \mathrm{~m}$ depth were assumed to be due to sardine shoals. Acoustic data analysis was restricted to the 10 to $50 \mathrm{~m}$ depth range, because (1) the vast majority of sardine were recorded above $50 \mathrm{~m}$ depth and (2) echo traces which were shaped differently from those of sardine shoals in the upper layer were observed sometimes below $50 \mathrm{~m}$ depth.

The scaled body length and body weight of the sardine collected were measured and used for calculations of target strength and biomass. Maturity data were also obtained from the samples, but they are described briefly in this paper. For further details on maturity, consult Aoki and Murayama $^{(2)}$ and Murayama et al. ${ }^{10)}$

Surface temperature data were collected along tracklines throughout the surveys with a continuous sea water temperature recorder. Temperature profiles were obtained from CTD casts. Sardine were distributed in the surface mixed layer, where temperature was similar to surface temperature.

The mean $S V$ was converted to the mean fish density using the following equations (1) and (2).

$$
\begin{gathered}
n=10^{0.1(S V-T S)} \\
T S=-68.2+20 \log F L
\end{gathered}
$$

where $n$ is the mean fish density in number (no. of fish $\left./ \mathrm{m}^{3}\right), S V$ the mean volume backscattering strength in $\mathrm{dB}, T S$ the target strength in $\mathrm{dB}$, and $F L$ the fork length in $\mathrm{cm}$. The $T S /$ length relationship at $50 \mathrm{kHz}$ was derived from Miyanohana $e t$ $a l .{ }^{11}$ Mean target strengths were obtained for 
Table 2. Body length and body weight of sardine sampled and target strength calculated according to Miyanohana et al. ${ }^{11}$

\begin{tabular}{ccccc}
\hline Cruise & Sample size & $\begin{array}{c}\text { Body length } \\
(\mathrm{cm}, \text { mean } \pm \mathrm{SD})\end{array}$ & $\begin{array}{c}\text { Body weight } \\
(\mathrm{g}, \text { mean } \pm \mathrm{SD})\end{array}$ & $\begin{array}{c}\text { Mean target strength } \\
(\mathrm{dB})\end{array}$ \\
\hline KT-90-3 & 71 & $19.5 \pm 0.93$ & $75.3 \pm 11.7$ & -42.0 \\
KT-91-1 & 65 & $19.7 \pm 0.62$ & $90.3 \pm 8.1$ & -41.9 \\
KH-91-2 Leg 1 & 200 & $19.2 \pm 0.72$ & $78.4 \pm 9.3$ & -42.1 \\
Leg 2 & 292 & $19.4 \pm 0.72$ & $85.2 \pm 11.6$ & -42.1 \\
KT-92-3 & 229 & $19.7 \pm 0.77$ & $85.1 \pm 12.2$ & -41.9 \\
\hline
\end{tabular}

each of the cruises using equation (2), with mean fork lengths calculated from mean scaled body lengths (fork length $=0.970 \times$ body length +1.44 , $r=0.926, n=20$ ) (Table 2). Next, the mean fish density in weight per unit surface area $\left(D, \mathrm{~g} / \mathrm{m}^{2}\right)$ was computed as follows.

$$
D=n \times B W \times R
$$

where $B W$ is the mean body weight in $g$, and $R$ the integration depth range, i.e. $40 \mathrm{~m}$. Hereinafter $D$ is referred to as the mean fish density.

\section{Results}

The mean $S V$ for the 10 to $50 \mathrm{~m}$ depth range and the $5 \mathrm{~nm}$ distance interval was calculated and converted to the mean fish density. The distributions of mean fish densities in 1990, 1991, and 1992 are illustrated along tracklines with isotherms (Figs. 1-3). The Kuroshio current region approximately corresponded to surface temperature $>20^{\circ} \mathrm{C}$. Each $5 \mathrm{~nm}$-segment was classified by observing echograms: one where echo traces of small pelagic schooling fish occurred, and the other where only weak diffuse scattering layers due to plankton appeared. The mean $S V$ in the former segment was converted to fish density, and for the latter segment fish density was defined as $D=0$.

In 1991, it is evident that sardine distribution varied during January-March as time advanced. Sardine occurred mostly in the coastal region where temperature $<19^{\circ} \mathrm{C}$ from late January to mid February (Fig. 2a, b). The pattern changed toward early March, when sardine were found offshore in the frontal and Kuroshio regions where temperature $>20^{\circ} \mathrm{C}$ (Fig. 2c). Then, in midMarch most sardine were again concentrated in the coastal waters $<19^{\circ} \mathrm{C}$, while a few shoals were found in the Kuroshio region (Fig. 2d). Comparing distribution patterns in the same period of early March among the 3 years, though fish densities were different, it is consistent that sardine

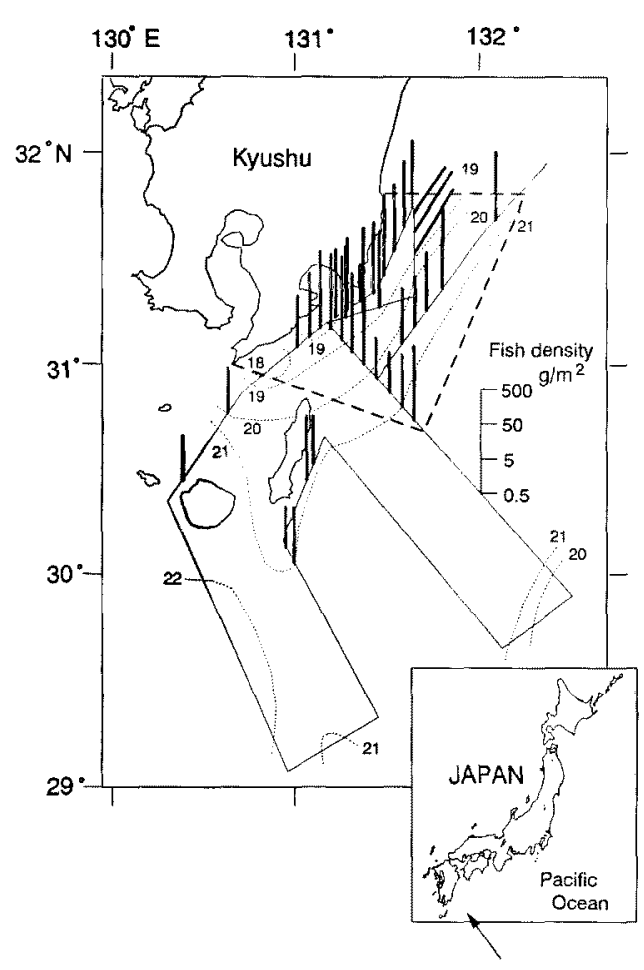

Fig. 1. Distribution of sardine densities off southern Kyushu during March 3-9, 1990.

Vertical bars show the mean densities of sardine $\left(\mathrm{g} / \mathrm{m}^{2}\right)$ for the $10-50 \mathrm{~m}$ depth range and $5 \mathrm{~nm}$ distance intervals. Thin solid lines: tracklines of the vessel; thin broken lines: surface isotherms in $1^{\circ} \mathrm{C}$ steps. For the area enclosed by bold broken lines sardine abundance was estimated in the 3 years 1990-1992.

shoals were generally aggregated in the inshore waters $<19^{\circ} \mathrm{C}$ along the coast of southern Kyushu and occurred occasionally in the offshore Kuroshio region (Figs. 1, 2d, 3).

Figure 4 shows variations in $S V$ and surface temperature along transects off Cape Hi-saki cros- 

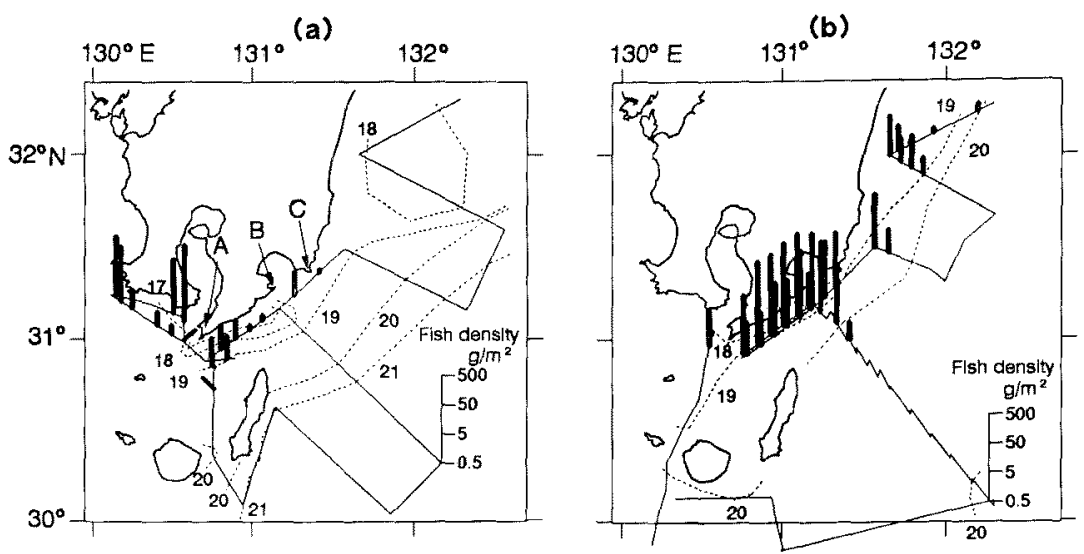

(c)

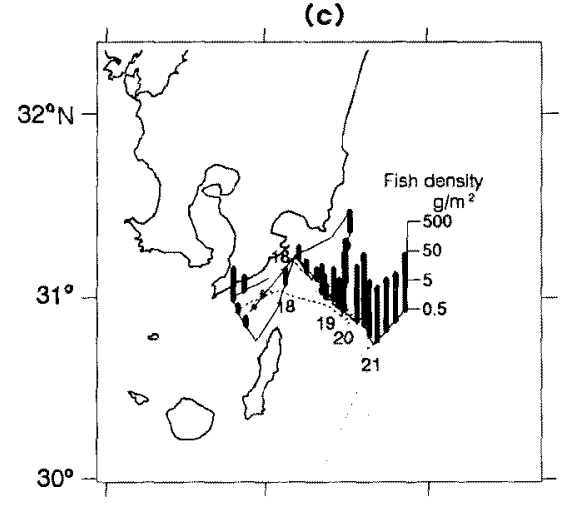

(d)

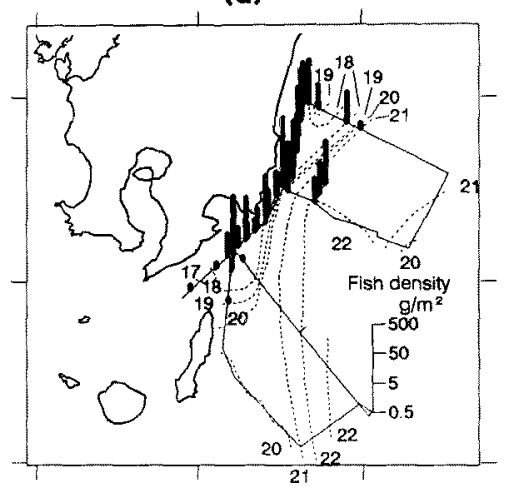

Fig. 2. Distribution of sardine densities off southern Kyushu during January-March, 1991. Vertical bars show the mean densities of sardine $\left(\mathrm{g} / \mathrm{m}^{2}\right)$ for the $10-50 \mathrm{~m}$ depth range and $5 \mathrm{~nm}$ distance intervals. Thin solid lines: tracklines of the vessel; thin broken lines: surface isotherms in $1^{\circ} \mathrm{C}$ steps. a: January $20-23$; b: February $14-17$ and 20 ; c: February 26-March 1; d: March 9-12. Locations of Cape Sata, Cape Hi-saki and Cape Toi are shown by $\mathrm{A}, \mathrm{B}$, and $\mathrm{C}$, respectively in panel (a).

sing the Kuroshio front. The $S V$ values were higher as a whole on the inshore side of the front than in the Kuroshio region beyond the front. It seems that the Kuroshio front acts as a barrier to the distribution of the sardine.

The results of the repeated surveys along the same transect crossing the Kuroshio front in 1991 indicated a change in sardine distribution (Fig. 5). From February 28 to March 1, the majority of sardine were concentrated in the Kuroshio waters $>20^{\circ} \mathrm{C}$, while sardine distribution was confined to the inshore side of the $20^{\circ} \mathrm{C}$ isotherm for other periods. At that time, the sardine moved offshore in response to an offshore shift in the Kuroshio current. The situation is illustrated in Fig. 6 by the distribution of $S V$ and the vertical ssection of temperature along the transect. Ovarian histologi- cal examinations of the female sample collected at the same times showed that most of them had either translucent hydrated eggs, new postovulatory follicles, or migratory nucleus oocytes, being about to spawn or in the act of spawning. On the other hand, another sample caught at a location $25 \mathrm{~nm}$ distant from the coast on February 25 contained only females having ovaries at the developing stage. The sardine distribution was closely associated with both water temperature and spawning activity. Also, in March 1990, ovarian histology indicated that spawning activity was higher in the Kuroshio region than in the inshore region. ${ }^{12)}$ Only 2 females were caught inshore in March 1992, and they were at the yolk stage. In conclusion, maturing sardine stayed on the inshore side of the Kuroshio front while spawning sardine 


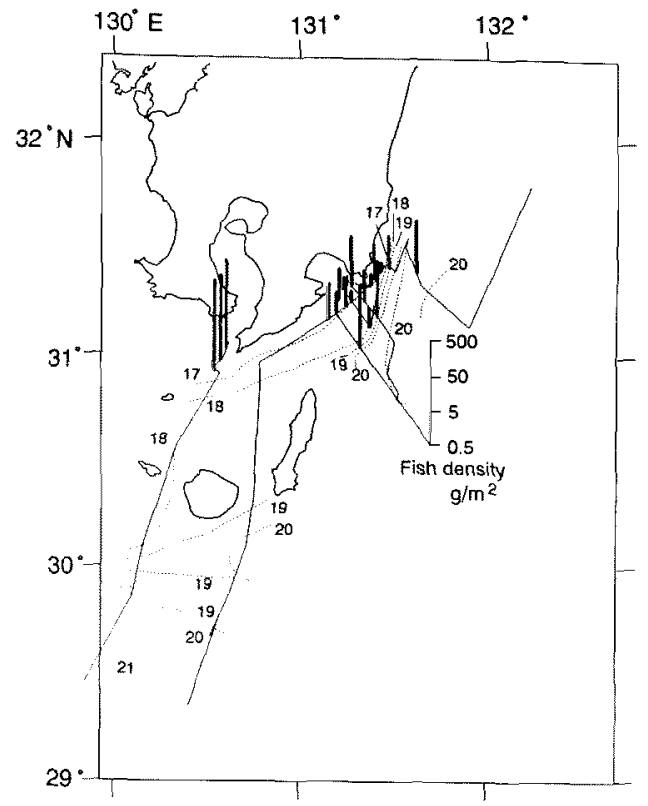

Fig. 3. Distribution of sardine densities off southern Kyushu during February 25-March 3, 1992.

Vertical bars show the mean densities of sardine $\left(\mathrm{g} / \mathrm{m}^{2}\right)$ for the $10-50 \mathrm{~m}$ depth range and $5 \mathrm{~nm}$ distance intervals. Thin solid lines: tracklines of the vessel; thin broken lines: surface isotherms in $1^{\circ} \mathrm{C}$ steps.

occurred in higher temperature offshore waters further than the Kuroshio front.

Fish abundance variations in time and space were further analyzed for the area east of Cape Sata from the fish density map shown in Fig. 2. The area was divided into 4 subareas by a southeastward line from Cape Toi and $20 \mathrm{~nm}$ distant line from the coast. (1) NI: inshore and north of Cape Toi, (2) NO: offshore and north of Cape Toi, (3) SI: inshore and south of Cape Toi, and (4) SO: offshore and south of Cape Toi. Generally, surface temperature was below $20^{\circ} \mathrm{C}$ within the $20 \mathrm{~nm}$ distance from the coast and above $20^{\circ} \mathrm{C}$ beyond the $20 \mathrm{~nm}$ distance.

As the survey area was varied, relative abundance rather than absolute abundance was considered for comparison in time and space. Fish aboundance $(B)$ can be expressed as

$$
B=\left(\overline{s v} / \overline{\sigma_{b s}}\right) \times m \times R \times A
$$

where $\overline{s v}$ is the mean volume backscattering coefficient $(10 \log \overline{s v}=\overline{S V})$ for the whole $5 \mathrm{~nm}$-segment where sardine echo traces were observed, $\overline{\sigma_{0 s}}$ the

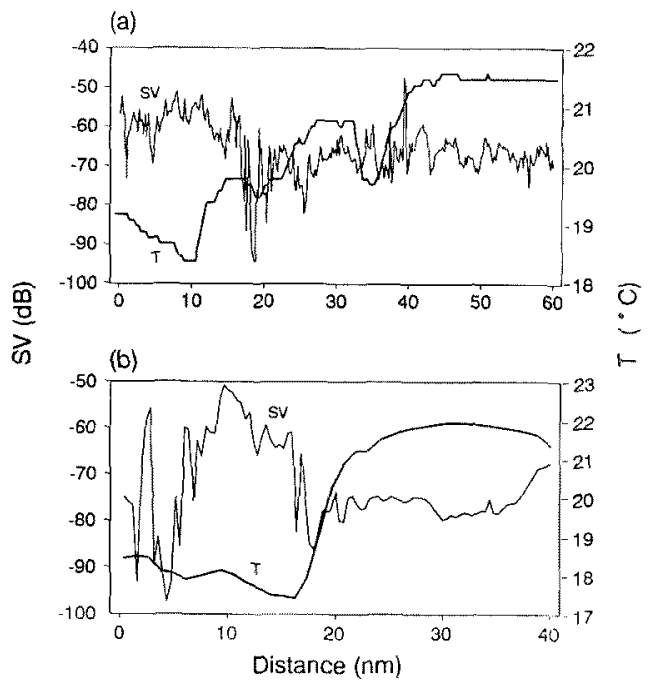

Fig. 4. Variations in volume scattering strength $(\mathrm{SV})$ and surface temperature (T) along a transect off Cape Hi-saki crossing the Kuroshio front.

$S V$ is the mean for the $10-50 \mathrm{~m}$ depth range and $0.2 \mathrm{~nm}$ (a) or $0.4 \mathrm{~nm}$ (b) distance intervals. a: $1639-2217 \mathrm{hr}$, March 3, 1990; b: 0640-0935 hr, March 14, 1991. The location of Cape Hi-saki is indicated in Fig. 2a.

mean backscattering cross section $\left(10 \log \overline{\sigma_{b s}}=\right.$ $\overline{T S}), m$ the number of $5 \mathrm{~nm}$-segments where sardine echo traces were observed, $R$ the integration depth range $(R=40 \mathrm{~m}), A$ the hypothetical area represented by one $5 \mathrm{~nm}$-segment. As $R$ and $A$ are constant, $\left(\overline{s v} / \overline{\sigma_{b s}}\right) \times m$ is proportional to sardine abundance. Next, fish abundance index $(B I)$ was defined as

$$
\begin{aligned}
B I & =10 \log \left(\left(\overline{s v} / \widehat{\sigma_{b s}}\right) \times m\right) \\
& =\overline{S V}-\overline{T S}+10 \log m
\end{aligned}
$$

The abundance index in the inshore areas increased by about 2 orders of magnitude $(18 \mathrm{~dB})$ in mid-February compared with those in late January, and it was higher in the southern area than in the northern area (Fig. 7). At the beginning of March sardine in the SO subarea were 20 times $(13 \mathrm{~dB})$ as abundant as those the SI subarea. In mid-March the abundance index showed a tendency to increase in the northern areas in contrast to February. These variations in relative fish abundance in the 4 subareas probably reflected fish movements in the spawning season.

Fish abundance was estimated for the same area where sardine occurred most frequently and 


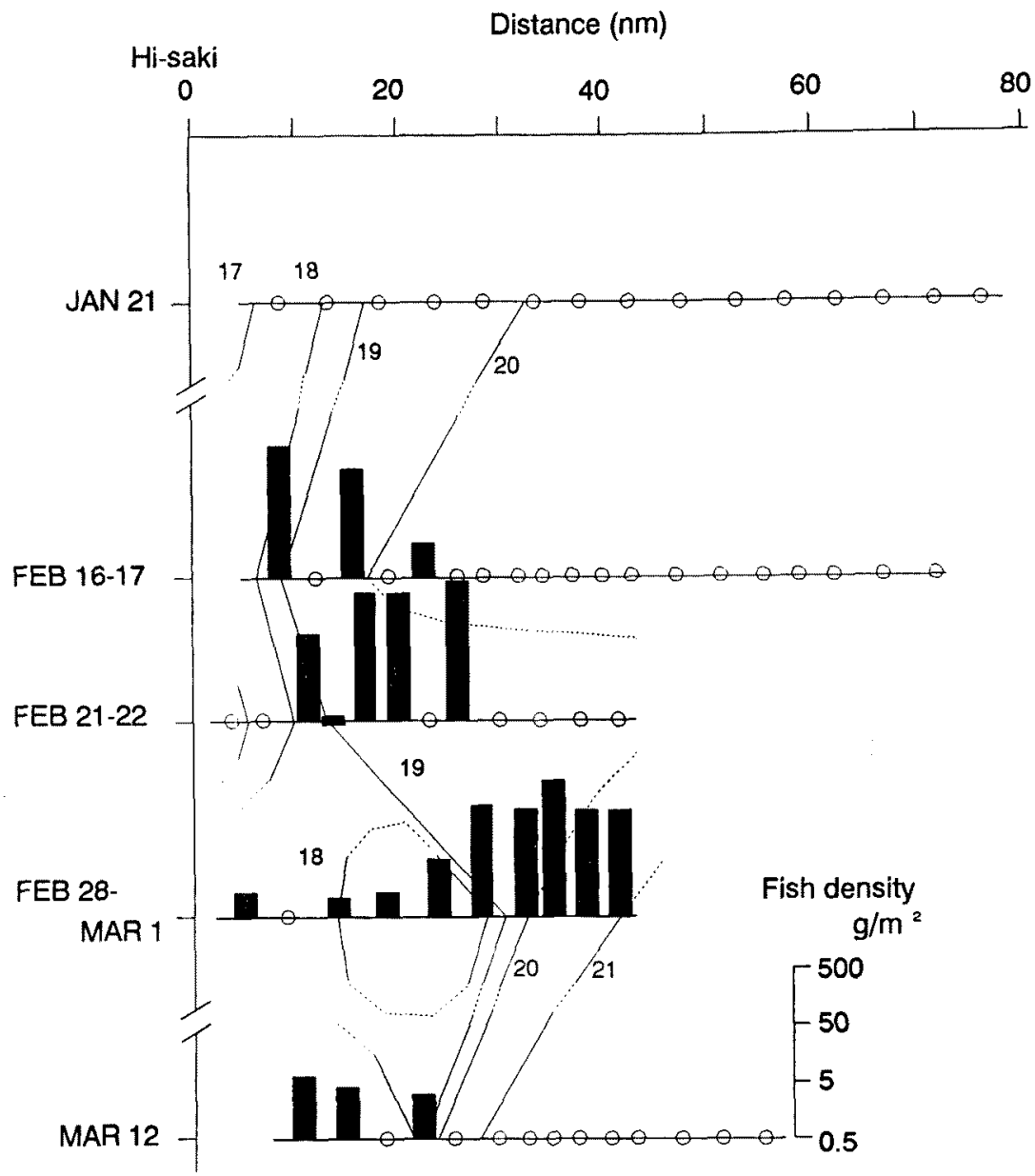

Fig. 5. Change in fish densities along the same transect crossing the Kuroshio front during January-March, 1991.

The mean densities of sardine $\left(\mathrm{g} / \mathrm{m}^{2}\right)$ for the $10-50 \mathrm{~m}$ depth range and $5 \mathrm{~nm}$ distance intervals are given. Isotherms in $1^{\circ} \mathrm{C}$ steps are also shown. Small circles denote no fish shoal. The location of Cape Hi-saki is indicated in Fig. 2a.

for the same period in the 3 years 1990-1992 (Table 3). The estimates were obtained by simply averaging fish densitives within this area and by multiplying it by the area. The estimated spawning biomass in this area decreased annually, and in 1992 it reached only $6 \%$ of the level of 1990 .

\section{Discussion}

Acoustic surveys in the spawning grounds off southern Kyushu in 1990-1992 indicated that the distribution of the spawning population of the Japanese sardine was closely associated with water temperature or the Kuroshio front, and that its abundance decreased markedly over the 3 years. Especially, repeated surveys during January-March 1991 revealed that sardine were aggregated on the lower temperature inshore side of the Kuroshio front at the beginning and end of the spawning season, and that the majority of spawning sardine occurred in the Kuroshio region where temperature $>20^{\circ} \mathrm{C}$ in the peak spawning period. The physiology of spawning seems to change the preference for temperature. Spawning sardine crossed the Kuroshio front, even though it appeared to have acted as a barrier to distribution till then. Around 1950, when stock levels were low, the Japanese sardine spawned inshore on the con- 


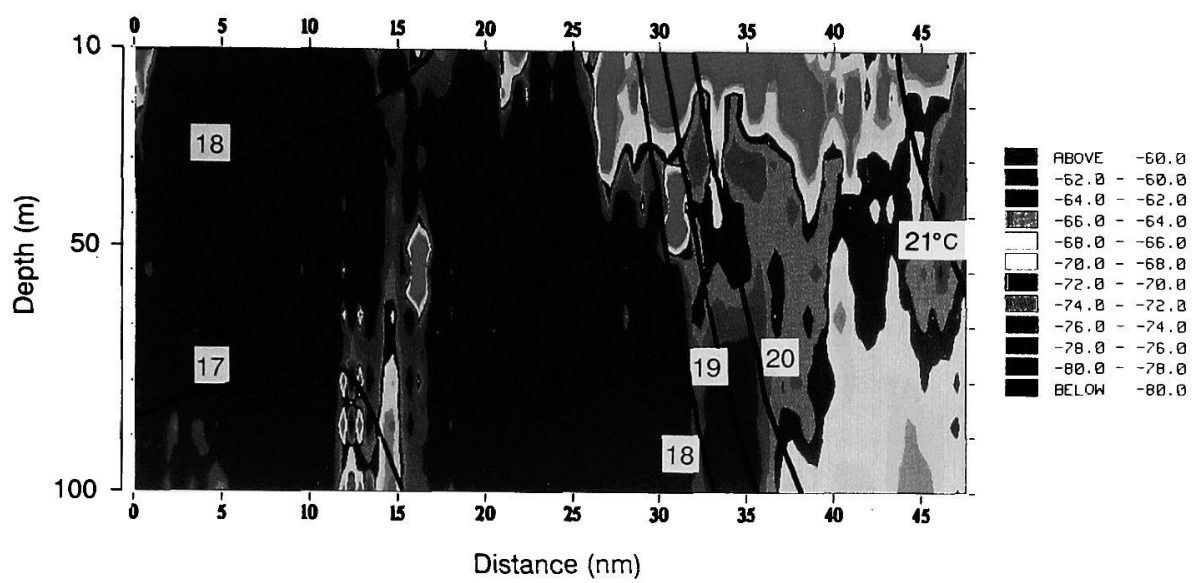

Fig. 6. Distribution of volume scattering strength $(S V)$ along the same transect as in Fig. 5 crossing the Kuroshio front February 28-March 1, 1991.

Averaged $S V$ values for $10 \mathrm{~m}$ depth strata and $0.2 \mathrm{~nm}$ distance intervals are shown in a color scale of 12 steps in $\mathrm{dB}$. Vertical section of temperature from CTD casts is superimposed.

Table 3. Fish abundance estimates with acoustics for the same period in the three years, 1990-1992

\begin{tabular}{llccc}
\hline \multicolumn{1}{c}{ Cruise } & \multicolumn{1}{c}{ Date } & $\begin{array}{c}\text { Distance of transects } \\
(\mathrm{nm})\end{array}$ & $\begin{array}{c}\text { Mean density } \\
95 \% \text { CI }\left(\mathrm{g} / \mathrm{m}^{2}\right)\end{array}$ & $\begin{array}{c}\text { Fish abundance } \\
95 \% \text { CI (t) }\end{array}$ \\
\hline KT-90-3 & MAR 3-9, 1990 & 195 & $40.2 \pm 11.9$ & $319,000 \pm 94,000$ \\
KH-91-3 Leg 3 & MAR 9-12, 1991 & 140 & $5.98 \pm 3.81$ & $47,000 \pm 30,000$ \\
KT-92-3 & FEB 27-MAR 2, 1992 & 205 & $2.48 \pm 1.15$ & $20,000 \pm 12,000$ \\
\hline
\end{tabular}

The Area in which fish abundances were calculated is shown in Fig. 1. Area $=7.94 \times 10^{3} \mathrm{~km}^{2}$,

tinental shelf. ${ }^{13)}$ The Japanese sardine probably changed their spawning behavior in response to increased population size.

During the period of high abundance in the $1930 \mathrm{~s}$, the sardine catches recorded a peak in 1936. Later, sardine stock declined abruptly and the spawning grounds off southern Kyushu disappeared in 1941. ${ }^{1}$ ) Our survey in 1992 showed that a much smaller number of sardine shoals occurred inshore. The spawning grounds south of Kyushu disappeared as soon as in the $1930 \mathrm{~s}$ after the peak abundance.

According to egg surveys by the Nansei National Research Institute of the Fishery Agency during February-March, sardine egg abundance off southern Kyushu decreased distinctly in 1991 against that in 1990 and declined to an extremely low level in 1992. ${ }^{14,15)}$ The change in fish abundance esti- mates in 1990-1992 in our study is consistent with the results of these egg surveys. On the other hand, many sardine eggs were observed off Shikoku and Kii Strait in 1992, as in 1990 and 1991, ${ }^{15}$ ) Additionally, sardine catches from the waters east of Kyushu during February-March did not decrease in 1990-1992.*2 These facts indicate that the sardine no longer migrated to spawn so far as south of Kyushu in 1992. While the nearshore temperature off southern Kyushu in March was slightly higher in 1990 than in 1991 and 1992 (Figs. 1-3), it showed no certain tendency in February 1990-1992.*2 The observed decline of abundance of spawning sardine off southern Kyushu was probably related to the sharp decrease in population size reflected by the catches rather than to oceanographic conditions.

There are some assumptions and potential

*2 Annual Reports of Fishing and Oceanographic Conditions, Miyazaki Prefectural Fishery Experimental Station $(1991,1992,1993)$. (in Japanese) 

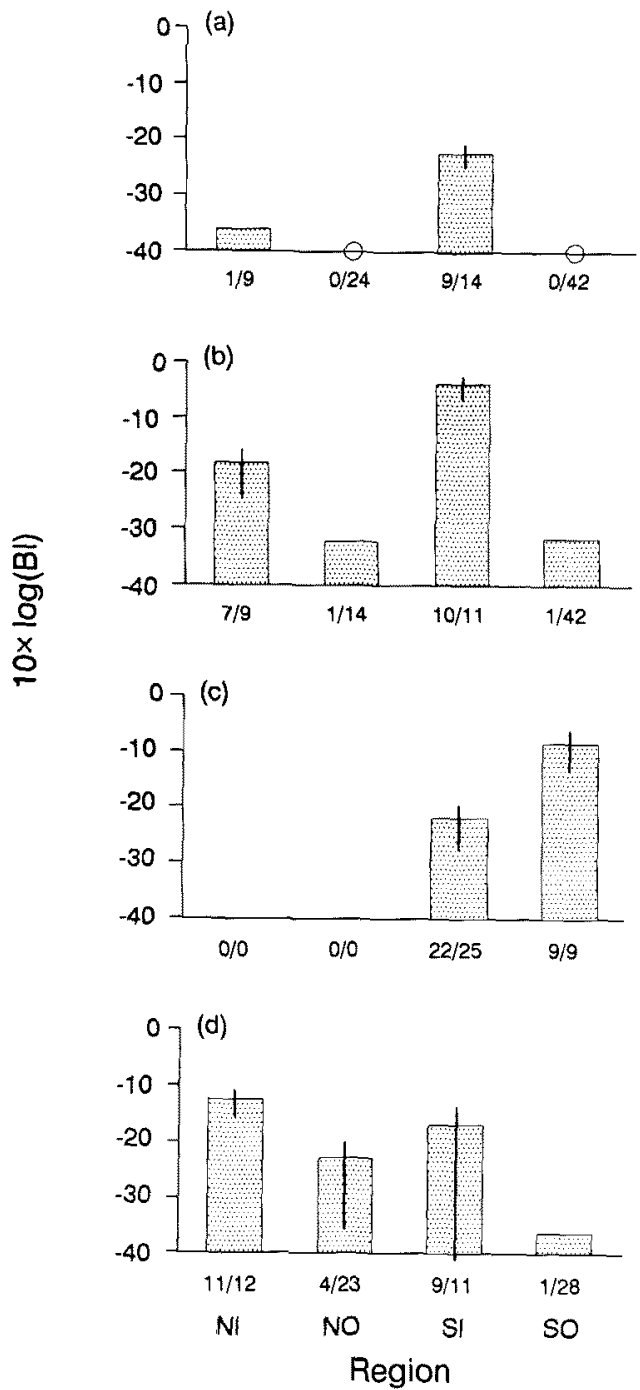

Fig. 7. Comparison of mean relative fish abundance (BI) in the 4 subarea east of Cape Sata, southern Kyushu during January-March, 1991.

$95 \%$ confidence intervals are shown by vertical bars. Numerals below each column indicate (no. 5 nm-segment where shoals appeared)/(no. of $5 \mathrm{~nm}$-segment surveyed). a: January $20-23$; b: February $14-17$ and 20 ; $c$ : February 26-March 1; d: March 9-12. NI: inshore and northern subarea; NO: offshore and northern subarea: SI: inshore and southern subarea; SO: offshore and southern subarea.

sources of error in estimating fish abundance because of certain limitations in the current acoustic method.
The numerical estimates of sardine density were restricted to a depth range of $10-50 \mathrm{~m}$. Echoes from the upper $10 \mathrm{~m}$ of water column were excluded from this analysis because of the near surface noise. Since few echo traces of pelagic fish shoals were found above a depth of $10 \mathrm{~m}$, mean fish densities in the $10-50 \mathrm{~m}$ depth range were not extrapolated to near the surface. It is impossible to identify individual targets such as sardine directly. We estimated densities of sardine above a depth of $50 \mathrm{~m}$ to exclude fish other than sardine. The restriction to the $10-50 \mathrm{~m}$ depth range may be a source of underestimation. The following, on the other hand, may lead to overestimation: echoes from plankton in $5 \mathrm{~nm}$-segments where fish shoals were observed were not excluded in calculating fish densities, and all of the fish traces above a depth of $50 \mathrm{~m}$ were assumed to be due to sardine shoals. To establish the reliability of acoustic estimation new procedures should be developed to identify species of individual targets and to separate the fish concerned from background biological noise due to plankton.

It has been generally accepted that it is preferable for target strengths to be measured in stitu. Unfortunately, the acoustic systems used in this study were insufflcient to carry out in situ measurement. The in situ measurement of target strengths is constrained by the condition that fish are dispersed enough to make resolution of single targets easy. It is generally difflcult to obtain adequate numbers of target strength measurements for small pelagic fishes schooling cohesively such as sardine. The empirical relationship for the lengthnormalized target strength used in this study was based on the measurements of sardine, which were $11-24 \mathrm{~cm}$ in fork length, tethered in a tank, and on averaging values for tilt angles with a mean of $5^{\circ}$ head-down and SD of $15^{\circ} .11$ The target strength varies with the tilt agngle of the fish. Diurnal variations in the tilt angle are presumed. Japanese anchovy in the night-time have been observed to have tilt angles with a mean of about $10^{\circ}$ head-up and SD of about $25^{\circ},{ }^{18)}$ There is no available data on sardine tilt angles while swimming. More observations of the behavior of individual fish in the sea are needed to understand variations in target strength. Also, it is important to use lower frequencies at which target strength is less influenced by tilt angle. ${ }^{17)}$

In this study, survey grids were not designed statistically to provide estimates of total spawner biomass off southern Kyushu. Fish abundance 
estimates in the 3 years were limited to the certain area where sardine shoals were most concentrated. The estimates by simply averaged fish densities had large confidence intervals because of a small number of transects. We only occasionally surveyed the western area south of Kyushu, where fish shoals were also observed. As is evident in the surveys, fish abundance in the western area south of Kyushu was never negligible. Jolly and Hampton $^{182}$ have shown that valid estimates can be obtained by taking a stratified random sample of parallel transects. A cruise needs to be carried out with survey grids designed adequately for acoustic assessment of total sardine spawner biomass.

\section{Acknowledgements}

We are grateful to Dr. Tsukasa Murayama of National Research Institute of Fisheries Engineering, who assisted in the acquisition of maturity data. Thanks are also due to the officers and crew of the RV 'Tansei Maru' and RV 'Hakuho Maru' of the Ocean Research Institute for their help and support.

\section{References}

1) Z. Nakai: Studies relevant to mechanisms underlying the fuctuation in the catch of the Japanese sardine, Sardinops melanosticta (Temminck \& Schlegel). Jap. J. Ichthyol., 9, 1-115 (1962).

2) K. Kuroda: Yearly changes of the main spawning grounds of the sardine, Sardinops melanostictus (T. et S.) in the waters along the Pacific coast of southern Japan. Bull. Japan. Soc. Fish. Oceanogr., 52, 289-296 (1988).

3) F, Hanaoka and $Y$. Konoshi: Distributions of spawning grounds, eggs and larvae of sardine in the southwestern Japan, Report of Pelagic Fish Resources Investigations by the Fisheries Agency, Tokyo, 1988, pp. 59-71 (in Japanese).

4) K. Kondo, Y. Hori, and K. Hiramoto: Life pattern of the Japanese sardine, Sardinops melanosticta (Temminck et Schlegel), and its practical procedure of marine researches of the stock (2nd Edition), Japan Fisheries Resource Conservation Association, Tokyo, 1976, pp. 1-67.
5) K. Kondo: On the mode of distribution and migration of the Japanese sardine, Sardinops melanostictus (Temminck \& Schlegel), at high level stock size. Bull. Tokai Reg. Fish. Res. Lab., 124, 1-33 (1988).

6) K. Kuroda: Studies on the recruitment process focusing on the early life history of the Japanese sardine, Sardinops melanostictus (Schlege1), Bull. Natl. Res. Inst. Fish. Sci., 3, 25-278 (1991).

7) K. Kuroda: Occurrence of the mature sardine, Sardinops melanostictus, around the Kuroshio Current in recent years. Bull. Japan. Soc. Fish. Oceanogr, 51, 373-376 (1987).

8) E. E. Francois and G. R. Garrison: Sound absorption based on ocean measurements. Part 2: Boric acid contribution and equation for total absorption. J. Acoust. Soc. Am., 72, 1879 1890 (1982).

9) I. Aoki and T. Murayama: Spawning pattern of the Japanese sardine Sardinops melanostictus off southern Kyushu and Shikoku, southwestern Japan. Mar. Ecol. Prog. Ser. 97, 127-134 (1993).

10) T. Murayama, M. Shiraishi, and I. Aoki: Changes in ovarian development, GSI, egg diameter and plasma levels of sex steroid hormones in the wild female Japanese sardine (Sardinops melanostictus) during spawning period. J. Fish. Biol. (submitted).

11) Y. Miyanohana, K. Ishii, and M. Furusawa: Measurements and analyses of dorsal-aspect target strength of six species of fish at four frequencies Rapp. P.- v. Reun. Cons. int. Explor. Mer, 189, 317-324 (1990).

12) I. Aoki and T. Murayama: Distribution and maturation of the spawning sardine, Sardinops melanostictus in the waters off southern Kyushu of Japan. Bull. Japan. Soc. Fish. Oveanogr., 55, 93-104 (1991).

13) Z. Nakai, S. Usami, S. Hattori, Y. Honjo, and S. Hayashi Progress Report of the Cooperative /washi Resources Investigations, Tokai Reg. Fish. Res. Lab., Tokyo, 1955, pp. 1-84.

14) M. Ishida: Distributions of eggs and larvae of fishes in the area of southwestern Japan in the winter and spring of 1991 Annual Report of Eggs, Latvae and Plankton Surveys in Central Block, National Research Institute of Fishery Science, No. 12, 88-93 (1991) (in Japanese).

15) M. Ishida: Distributions of eggs and larvae of fishes in the area off southwestern Japan in the winter and spring of 1992. Annual Report of Eggs, Larvae and Plankton Surveys in Central Block, National Research Institute of Fishery Science, No. 12, 1-7 (1991) (in Japanese).

16) I. Aoki and T. Inagaki: Photographic observations on the behaviour of Japanese anchovy Engraulis japonica at night in the sea. Mar. Ecol. Prog. Ser., 43, 213-221 (1988).

17) M. Furusawa: Study on echo sounding for estimating fisheries resources. Bull. Nat. Res. Inst. Fish. Eng., 11, 173-249 (1990).

18) G. M. Jolly and I. Hampton: A stratified random transect design for acoustic surveys of fish stocks. Can. J. Fish. Aquat. Sci., 47, 1282-1291 (1990). 